\title{
Comparative Neuropsychology of Cortical and Subcortical Dementia
}

\author{
Morris Freedman and Marlene Oscar-Berman
}

\begin{abstract}
The terms "cortical" and "subcortical" dementia are controversial; however, the clinical distinction between them is real. For example, although Alzheimer's and Parkinson's disease (prototypical of cortical and subcortical dementia, respectively) share clinical features, they differ in the presence of aphasia, apraxia, and agnosia in Alzheimer's disease but not in Parkinson's dementia. We review our studies aimed at clarifying the mechanisms underlying the differences between these neurological disorders. Experimental paradigms adopted from animal models were used to study the functional anatomy and neuropsychological characteristics of Alzheimer's and Parkinson's disease. The tasks administered include delayed alternation (DA) and delayed response (DR), which are sensitive to frontal system damage, and tactile discrimination learning (TOL) and reversal (TRL) paradigms sensitive to parietal system damage. Alzheimer's patients were significantly impaired on all tasks whereas Parkinsonians with dementia were impaired only on DR and TRL. Consideration of neuroanatomical and neuropsychological mechanisms involved in DA, DR, TOL, and TRL appears to have sharpened the distinction between Alzheimer's and Parkinson's dementia. Dementia in Alzheimer's disease may involve dorsolateral frontal, orbitofrontal and parietal systems. In contrast, dementia in Parkinson's disease may involve prominent dorsolateral frontal system damage.
\end{abstract}

\begin{abstract}
RÉSUMÉ: Neuropsychologie comparative des démences corticales et sous-corticales. Les termes démence "corticale" et "sous-corticale" sont des termes controversés; cependant, la distinction clinique entre les entité qu'ils désignent est réelle. Même si la maladie d'Alzheimer et la maladie de Parkinson par exemple (respectivement prototypes de la démence corticale et sous-corticale), ont des manifestations cliniques communes, elles diffèrent par la présence d'aphasie, d'apraxie et d'agnosie dans la maladie d'Alzheimer et leur absence dans la démence du Parkinson. Nous revoyons nos études visant à clarifier les mécanismes sous-jacents aux différences entre ces entités neurologiques. Nous avons utilisé des paradigmes expérimentaux adaptés des modèles animaux pour étudier l'anatomophysiologie et les caractéristiques neuropsychologiques de la maladie d'Alzheimer et de la maladie de Parkinson. Parmi les épreuves administrées citons: l'alterance différée (AD) et la réponse différée (RD) qui sont des épreuves très sensibles à l'atteinte du système frontal; l'apprentissage de la discrimination tactile (ADT) et l'apprentissage de l'inversion tactile (AIT) qui sont des paradigmes sensibles à l'atteinte du système pariétal. Toutes les épreuves étaient significativement anormales chez les patients souffrant de la maladie d'Alzheimer, alors que seulement les épreuves de la RD et de l'AIT étaient altérées chez les parkinsoniens. L'étude des mécanismes neuro-anatomiques et neuropsychologiques impliqués dans l'AD, la RD, l'ADT et l'AIT semble avoir précisé la distinction entre la démence de la maladie d'Alzheimer et celle de la maladie de Parkinson.
\end{abstract}

Can. J. Neurol. Sci. 1986; 13:410-414

Comparative Neuropsychology of Cortical and Subcortical Dementia

Although non-human animal models have long supported a role for focal cortical and subcortical brain structures in a variety of cognitive functions ${ }^{1-3}$ it is only recently that parallel concepts have emerged linking circumscribed pathology to intellectual deficits in humans with neurological disease. ${ }^{\text {4-6 }}$ The anatomical and physiological mechanisms underlying these intellectual deficits, however, are poorly understood. "Subcortical dementia", the term originally applied to the constellation of human cognitive deficits attributed to subcortical brain damage is characterized by 1) memory loss;2) impaired manipulation of acquired knowledge (i.e. calculating and abstracting ability); 3) personality changes marked by apathy and inertia; and 4) general slowness of thought processes. ${ }^{4}$ In contrast to subcortical dementia is the concept of "cortical dementia" which refers to the pattern of cognitive deficits attributed to pathology in the cerebral cortex ${ }^{4,5}$ The cortical dementias share many features with subcortical dementia, but are distinguished from subcortical dementia by the presence of aphasia, apraxia and agnosia. ${ }^{7}$

Although useful clinical concepts, ${ }^{7,8,9}$ subcortical and cortical dementia have been challenged as valid anatomical entities

From the Department of Medicine (Division of Neurology), University of Toronto; Mount Sinai Hospital; and Baycrest Centre for Geriatric Care (Dr. Freedman) and Psychology Service, Boston Veterans Administration Medical Centre, and Department of Neurology and Division of Psychiatry, Boston University School of Medicine (Dr. Oscar-Berman)

Reprint requests to: Dr. Morris Freedman, Mount Sinai Hospital, Suite 433, 600 University Avenue, Toronto, Ontario, Canada M5G 1X5 
on the basis of neuropathological data. Reports have shown that cortical lesions may be important in the pathogenesis of subcortical dementia and that subcortical lesions may be significant in cortical dementia. For example, in Alzheimer's disease, the prototype of cortical dementia, there is a loss of cholinergic neurons in the nucleus basalis of Meynert, ${ }^{10}$ a subcortical structure in the basal forebrain. This nucleus is the major source of cholinergic innervation to the cerebral cortex. ${ }^{11-14}$ The clearly demonstrated involvement of the cholinergic system in memory ${ }^{15-20}$ supports the concept that the nucleus basalis of Meynert is important for cognitive function. Likewise, Parkinson's and Huntington's disease, the two most thoroughly studied neurological disorders characterized by the classical behavioural pattern of subcortical dementia, both involve damage in cortical regions. Neurofibrillary tangles and senile plaques have been well-documented in the cerebral cortex in Parkinson's disease, ${ }^{21-23}$ and cortical cell loss and gliosis are seen in Huntington's disease. ${ }^{24}$

The major issue surrounding the controversy about the validity of subcortical and cortical dementias as distinct clinical entities has been therefore, the nature of the underlying neuropathology rather than the neuropsychological mechanisms underlying these two forms of cognitive impairment. Since traditional behavioural experimental approaches have not been successful in resolving this issue, we employed a different strategy involving a direct application of experimental paradigms adopted from the animal literature to the study of neurobehavioural patterns of human cortical and subcortical dementia. Termed comparative neuropsychology, ${ }^{25-27}$ the approach is based upon techniques that have a long history of proven reliability and validity in demonstrating brain-behaviour relationships in non-human primates. Within the last five years these same techniques have clearly established themselves as valuable tools for identifying cognitive impairment in brain damaged humans. ${ }^{26.28-32}$ The use of animal models to study humans with dementia, therefore, not only draws upon a rich and extensive literature, but also allows for greatly needed direct comparisons of behavioural deficits observed in humans and animals with damage of homologous brain structures. Aspects of our use of the comparative neuropsychology approach $^{33,34}$ to study cortical and subcortical dementia will be the subject of this review. We selected Alzheimer's disease as the model for cortical dementia and Parkinson's disease as the model for subcortical dementia. When making our comparisons we were careful to equate the groups for severity of dementia.

We employed experimental paradigms which have been validated for the demonstration of deficits linked to damage in two different brain systems implicated in Alzheimer's and Parkinson's disease: 1) the prefrontal cortical/subcortical system, and 2) the parietal cortical/subcortical system. The tasks associated with frontal system functions consisted of delayed alternation (DA) and delayed response (DR). ${ }^{28,31,35}$ All of our tasks will be described later, but it should be noted that different aspects of each of them are mediated by separate cortical/subcortical neuronal networks. ${ }^{2,36-40}$ For assessment of parietal system functions we used tactile discrimination learning (TOL) and reversal (TRL) paradigms. TOL is sensitive to bilateral parietal lobe lesions in non-human primates, ${ }^{40}$ and TRL provides a measure or perseveration with touch as in the input modality. Although both Alzheimer's and Parkinson's patients with dementia were expected to demonstrate behavioural changes consistent with frontal lobe damage, we hypothesized that the nature of the impairment would be different and that this would be reflected by distinct performance profiles on the DA and DR tasks. We also predicted that the patients with Alzheimer's and Parkinson's dementia would show different performance profiles on the tactile learning paradigm (the measure of parietal lobe function) based on clinical, neuropathological ${ }^{41}$ and positron emission tomography (PET) scanning ${ }^{42,43}$ data which suggest that parietal lobe impairments are prominent in Alzheimer's disease. In contrast, the dementia of Parkinson's disease is characterized by prominent frontal lobe deficits. ${ }^{9} \mathrm{We}$, therefore, hypothesized that the profiles of the subjects studied using paradigms adopted from animal models would serve to differentiate Alzheimer's from Parkinson's dementia at a behavioural level and that the performance profile would also provide insights into the anatomical mechanisms underlying the behavioural deficits.

\section{METHODS}

We compared the performance of patients with idiopathic Parkinson's disease and dementia $(n=15)$ with that of patients with Alzheimer's disease $(n=14)$, Parkinson's disease without dementia $(n=13)$ and normal controls $(n=22)$. All 64 subjects participated on the DA and DR tasks. However, 3 patients with Alzheimer's disease and 2 with Parkinson's disease and demen. tia did not participate in the tactile learning experiments. The Parkinsons' patients were separated into demented and nondemented groups on the basis of their performance on the Mattis Dementia Rating Scale. ${ }^{44}$ The criterion for dementia was determined on the basis of normative data obtained from the 22 normal controls. Parkinson's patients with scores falling below the range of scores attained by any of the normal controls (133-144) were classified as having dementia. The patients with Alzheimer's disease were equated for severity of dementia to the patients with Parkinson's disease and dementia, using the Dementia Rating Scale. Detailed patient descriptions can be found elsewhere. ${ }^{33,34}$

The methodology for DA and DR tasks has been described in detail. ${ }^{33}$ The apparatus and stimuli were the same in both tasks but the experimental procedures differed. Briefly, on DA, subjects were required to find a penny in one of two reinforcement wells by learning that the location of the penny was being alternated by the experimenter from side to side after each correct response. The reinforcement wells were each covered by an identical black lid and were placed $23.5 \mathrm{~cm}$ apart in a wooden frame. There was a 5 second inter-trial interval. Testing continued until subjects discovered that the penny was being alternated from side to side to a learning criterion of 12 consecutive correct responses or until a failure criterion of 50 trials (i.e. they did not solve the problem after 50 trials).

On DR, subjects were required to retrieve the penny following a delay of $0,10,30$ or 60 seconds, respectively, after seeing it being placed, according to a modified random sequence, ${ }^{45}$ under one of the two black lids. During the delay period the covered wells were hidden from view by a curtain. Learning criterion was 9 correct responses in a block of 10 trials on each delay condition and failure criterion was 40 trials on each delay condition.

For the tactile learning experiment ${ }^{34}$ there were two components, TOL and TRL. On TOL subjects were required to find a 
penny under one of two wells covered by a lid, as before. However, the lids were hidden from view by a curtain and the subjects had to identify the correct lid using tactile information obtained by palpating a raised pattern on its surface ( $X$ vs $O$ ). One of the two patterns was considered "correct" and always had the penny underneath it. The patterned lids appeared in the left and right positions according to a modified random schedule. ${ }^{45}$ Subjects continued until they made 9 correct responses in a block of 10 trials or until a failure criterion of 200 trials. After subjects completed the TOL task, TRL began. The pattern that was not reinforced initially became the reinforced stimulus (i.e. correct stimulus) and subjects had to reverse what they originally learned and find the penny under the other lid. Learning criterion again was 9 correct trials in a block of 10 trials, and failure criterion was 50 trials. After the subject completed this first reversal problem there followed 3 other successive reversal problems, each with the same learning and failure criteria.

\section{RESULTS}

Detailed results have been reported ${ }^{33,34}$ elsewhere and will only be summarized here (Table 1). The Parkinson's patients with dementia had significant deficits on DR but not on DA, whereas the Alzheimer patients were impaired on both tasks. TOL was significantly more impaired in the Alzheimer's compared to the demented Parkinson's patients. Both Alzheimer's and demented Parkinson's patients were impaired on TRL but the Alzheimer patients showed significantly more perseverative type errors than did the Parkinson's patients.

The observed deficits cannot be attributed to group differences in age or education since these variables were included as co-variates in the regression analyses used to analyze the data.

\begin{tabular}{|c|c|c|c|}
\hline & \multirow[b]{2}{*}{$\begin{array}{l}\text { Delayed } \\
\text { Response }\end{array}$} & \multicolumn{2}{|c|}{ Tactile Learning } \\
\hline $\begin{array}{c}\text { Delayed } \\
\text { Alternation }\end{array}$ & & $\begin{array}{c}\text { Original } \\
\text { Learning }\end{array}$ & $\begin{array}{l}\text { Reversal } \\
\text { Learning }\end{array}$ \\
\hline
\end{tabular}

\begin{tabular}{llllll}
\hline $\begin{array}{l}\text { Alzheimer's } \\
\text { Disease }\end{array}$ & + & & + & + & + \\
\hline $\begin{array}{l}\text { Parkinson's Disease } \\
\text { with Dementia }\end{array}$ & - & & + & - & + \\
\hline $\begin{array}{l}\text { Parkinson's Disease } \\
\text { without Dementia }\end{array}$ & - & - & - & - & - \\
\hline Normal Controls & - & - & - & - \\
\hline+ deficit & & & & & \\
- no deficit & & &
\end{tabular}

- no deficit

\section{Discussion}

In Alzheimer's and Parkinson's disease with dementia we found distinct performance profiles on DA, DR and tactile discrimination learning even though both groups had been equated for severity of dementia. In Alzheimer's disease DA, DR, TOL and TRL were all significantly impaired whereas in Parkinson's disease with dementia there were significant deficits only on DR and TRL.

Although deficits on DR occur after lesions within both the dorsolateral frontal system and orbitofrontal system, they are more prominent following dorsolateral frontal damage. ${ }^{46,47}$ Mild deficits on DR can also be produced by lesions in the head of the caudate $^{1}$ and dorsomedial nucleus of the thalamus. ${ }^{48.49}$ The head of the caudate receives direct projections from dorsolateral frontal cortex ${ }^{50}$ The dorsomedial nucleus of the thalamus is also a well documented frontal projection site. ${ }^{51,52}$ Both subcortical structures are therefore part of the frontal projection system. Our findings on DR suggest that dorsolateral frontal cortex, or its related projection systems, are involved in the pathophysiology of the dementia in both Alzheimer's and Parkinson's disease. Since the head of the caudate nucleus is an integral component of the nigrostriatal system that is involved in Parkinson's disease,$^{53}$ it is reasonable to raise the question whether the critical lesion for the DR deficits in Parkinson's disease is in the head of the caudate rather than the prefrontal cortex or other frontal projection sites. In fact, the lesion may even be in the anterodorsal sector of the head of the caudate since this is the area to which dorsolateral frontal cortex primarily projects. ${ }^{50}$ It is noteworthy that, within the caudate nucleus in Parkinson's patients, it is the anterior portion of the caudate head which undergoes the most severe loss of dopamine concentration. ${ }^{54}$ Additional studies however, are needed to address this issue further.

Performance on DA is sensitive to lesions in the dorsolateral and orbitofrontal cortex,${ }^{35}$ head of the caudate, ${ }^{1.2}$ hippocampus, ${ }^{55}$ amygdala ${ }^{55}$ temporal cortex,${ }^{56}$ dorsomedial nucleus of the thalamus $^{48,49}$ and hypothalamus. ${ }^{3}$ Poor performance on DA has been related to abnormal perseverative responding. Since orbitofrontal lesions produce the most prominent deficits in perseveration, ${ }^{57}$ orbitofrontal system damage may be important in explaining the deficit on DA in Alzheimer's disease. Alternatively, the DA deficit in Alzheimer's disease may be related to one of the other multiple lesion sites implicated in DA deficits.

The finding that tactile learning of a new problem (TOL) was significantly impaired in patients with Alzheimer's disease compared to patients with idiopathic Parkinson's disease and dementia also supports the concept that there are selective differences between the patterns of impairment characterizing the dementias of Alzheimer's and Parkinson's disease. Comparative data from non-human animal models suggest that deficits in TOL are sensitive to lesions in the parietal lobes. ${ }^{40}$ Clinical data, as well as recent PET studies, ${ }^{42.43}$ and neuropathological data ${ }^{41}$ all suggest that parietal lobe involvement is prominent and appears early in the progression of Alzheimer's disease. In our studies, ${ }^{33.34}$ whereas only the Alzheimer patients were impaired in learning the original tactile discrimination (TOL), both the Alzheimer's and the demented Parkinson's groups were significantly impaired in their ability to use the reversal strategy. However, an analysis of error patterns of the two groups showed that there was a difference in the types of errors that they made. As expected, perseverative responding was a significantly greater factor in the deficits seen in the Alzheimer patients compared to all other groups; that is, they continued to choose the previously rewarded pattern despite a shift in reinforcement to the other stimulus. Since perseveration is associated with frontal lobe lesions, ${ }^{58}$ the perseverative tendency in the Alzheimer patients is likely due to the known frontal pathology in this disorder. ${ }^{58}$ The abnormal perseverative behaviour on the tactile task also supports the findings suggestive of frontal system deficits already reported in Alzheimer's dementia using DA and DR.

\section{Conclusion}

There is an increasing literature suggesting that there are separate mechanisms underlying the dementias of Alzheimer's 
and Parkinson's disease. ${ }^{60-62}$ The results of the studies reviewed here lend strong support to this notion. Although the labels "subcortical" and "cortical" for the cognitive deficits in Parkinson's and Alzheimer's disease may not be accurate from an anatomical point of view, the growing body of data suggests that the concept underlying these labels, i.e. that they represent distinct patterns of dementia, remains viable.

\section{ACKNOWLEDGEMENTS}

The studies reviewed were supported by the Medical Research Council of Canada, The Physicians Services Incorporated Foundation and the Gerontology Research Council of Ontario (Dr. Freedman), and by the Medical Research Service of the Veterans Administration (USA) and the following USDHHS grants to Boston University School of Medicine: NIAAA AA05211 and RSDA AA00061; NINCDS NS06209 and NS114408 (Dr. Oscar-Berman).

\section{REFERENCES}

1. Battig K, Rosvold HE, Mishkin M. Comparison of the effects of frontal and caudate lesions on delayed response and alternation in monkeys. J Comp Physiol Psychol 1960; 53: 400-404.

2. Divac 1, Rosvold HE, Szwarcbart MK. Behavioural effects of selective ablation of the caudate nucleus. J Comp Psysiol Psychol 1967; 63: 184-190.

3. Rosvold HE. The frontal lobe system: cortical-subcortical interrelationships. Acta Neurobiol Exp 1972; 32: 439-460.

4. Albert ML, Feldman RG, Willis AL. 'The subcortical dementia' of progressive supranuclear palsy. J Neurol Neurosurg Psychiatry 1974; 37: 121-130.

5. McHugh PR, Folstein MF. Psychiatric syndromes of Huntington's chorea: A clinical and phenomenologic study. In: Benson DF, Blumer D, eds. Psychiatric Aspects of Neurologic Disease. New York: Grune and Stratton 1975: 267-286.

6. Olton DS, et al, eds. Memory Dysfunctions: An Integration of Animal and Human Research from Preclinical and Clinical Perspectives. Annals of the New York Academy of Sciences 1985: vol 44.

7. Benson DF. The treatable dementias. In: Benson DF, Blumer D, eds. Psychiatric Aspects of Neurologic Disease. New York: Grune and Stratton 1975: 123-148.

8. Cummings JL, Benson DF. Subcortical dementia. Arch Neurol $1984 ; 41: 874-889$.

9. Freedman M, Albert ML. Subcortical dementia (Chap 19). In: Frederiks JAM, ed. Handbook of Clinical Neurology, vol 2(46). Amsterdam: Elsevier Science Publishers 1985: 311-316.

10. Whitehouse PJ, Price DL, Struble RG, et al. Alzheimer's disease and senile dementia: loss of neurons in the basal forebrain. Science 1982; 215: 1237-1239.

11. Divac I. Magnocellular nuclei of the basal forebrain project to neocortex, brainstem, and olfactory bulb. Review of some functional correlates. Brain Res 1975; $93: 385-398$

12. Jones EG, Burton H, Saper CB, et al. Midbrain diencephalic and cortical relationships of the basal nucleus of Meynert and associated structures in primates. J Comp Neurol 1976; 167: 385-420.

13. Kievet J, Kuypers HGJM. Basal forebrain and hypothalamic connections to frontal and parietal cortex in the rhesus monkey. Science 1975; 187: 660-662.

14. Shute CCD, Lewis PR. The ascending cholinergic reticular system: neocortical, olfactory and subcortical projections. Brain 1967; 90: $497-520$

15. Arendt T, Bigl V, Arendt A, et al. Loss of neurons in the nucleus basalis of Meynert in Alzheimer's disease, paralysis agitans and Korsakoff's Disease. Acta Neuropathol 1983; 61: 101-108.

16. Davis KL, Mohs RC, Tinklenberg JR, et al. Physostigmine: improvement of long-term memory processes in normal humans. Science 1978; 201: 272-274.

17. Drachman DA. Memory and cognitive function in man: does the cholinergic system have a specific role? Neurology 1970; 27: 783-790.
18. Drachman DA, Leavitt J. Human memory and the cholinergic system: a relationship to aging? Arch Neurol 1974; 30: 113-121.

19. Peters BH, Levin HS. Memory enhancement after physostigmine treatment in the aminesic syndrome. Arch Neurol 1977;34:215-219.

20. Peters BH, Levin HS. Effects of physostigmine and lecithen on memory in Alzheimer disease. Ann Neurol 1979; 6: 219-221.

21. Alvord EC, Forno LS, Kusske JA, et al. The pathology of parkinsonism: a comparison of degenerations in cerebral cortex and brainstem. Adv Neurol 1974; 5: 175-193.

22. Boller F, Mizutani T, Roessmann U, et al. Parkinson disease, dementia, and Alzheimer disease: clinicopathological correlations. Ann Neurol 1980; 7: 329-335.

23. Hakim AM, Mathieson G. Dementia in parkinson disease: a neuropathologic study. Neurology 1979; 29: 1209-1214.

24. Victor M. Discussion of "subcortical dementia". In: Katzman R, Terry RD, Bick KL, eds. Alzheimer's Disease: Senile Dementia and Related Disorders, New York: Raven Press 1978: 194.

25. Oscar-Berman M. Neuropsychological consequences of long-term chronic alcoholism. American Scientist 1980; 68: 410-419.

26. Oscar-Berman M, Zola-Morgan SM. Comparative neuropsychology and Korsakoff's syndrome. I. Spatial and visual reversal learning. Neuropsychologia 1980; 18: 499-512.

27. Weiskrantz LA. A comparison of hippocompal pathology in man and other animals. In: Functions of the Septo-hippocampal System. Ciba Foundation Symposium 58. New York: Elsevier 1978.

28. Freedman M, Oscar-Berman M. Bilateral frontal lobe disease and selective delayed-response deficits in humans. Behav Neuroscience 1986; 100: 337-342.

29. Oscar-Berman M,Zola-Morgan SM. Comparative neuropsychology and Korsakoff's syndrome. II. Two-choice visual discrimination learning. Neuropsychologia 1980; 18: 513-526.

30. Oscar-Berman M, Zola-Morgan SM, Öberg RGE, et al. Comparative neuropsychology and Korsakoff's syndrome. III. Delayed reponse, delayed alternation and DRL performance. Neuropsychologia 1982; 20: 187-202.

31. Pribram KH, Ahumada A, Hartog J, et al. A progress report on the neurological processes disturbed by frontal lesions in primates. In: Warren JM, Akert K, eds. The Frontal Granular Cortex and Behaviour. New York: McGraw-Hill Book Company 1964: 28-55.

32. Witt ED, Goldman-Rakic PS. Intermittent thiamine deficiency in the rhesus monkey: II. Evidence for memory loss. Ann Neurol 1983; 13: 396-401.

33. Freedman M, Oscar-Berman M. Selective delayed reponse deficits in Parkinson's and Alzheimer's disease. Arch Neurol 1986; 43: 886-890.

34. Freedman M, Oscar-Berman M. Tactile Discrimination Learning Deficits in Alzheimer's and Parkinson's Disease. Submitted for publication.

35. Warren JM, Akert K, eds. The Frontal Granular Cortex and Behaviour. New York: McGraw-Hill 1964.

36. Brutkowski S, Mishkin M, Rosvold HE. Positive and inhibitory motor conditioned reflexes in monkeys after ablation of orbital or dorsolateral surfact of the frontal cortex. In: Gutmann E, Hnik P, eds. Central and Peripheral Mechanisms of Motor Functions. Prague: Czechoslovak Academy of Sciences 1963.

37. Goldman PS, Rosvold HE, Vest B, et al. Analysis of the delayedalteration deficit produced by dorsolateral prefrontal lesions in the rhesus monkey. J Comp Physiol Psychol 1971; 77: 212-220.

38. Kling A, Tucker TJ. Sparing of function following localized brain lesions in neonatal monkeys. In: Isaacson RL, ed. The neuropsychology of development. New York: John Wiley \& Sons Inc. $1968 ; 121-145$.

39. Mishkin M. Effects of small frontal lesions on delayed alternation in monkeys. J Neurophysiol 1957; 20: 615-622.

40. Wilson M. Effects of circumscribed cortical lesions upon somesthetic and visual discrimination in the monkey. J Comp Physiol Psycho 1957; 50: 630-635.

41. Brun A, Englund E. Regional pattern of degeneration in Alzheimer's disease: Neuronal loss and histopathological grading. Histopathology 1981; 5: 549-564.

42. Chase TN, Foster NL, Fedio P, et al. Regional cortical dysfunction in Alzheimer's disease as determined by positron emission tomography. Ann Neurol 1984; 15 (supplement: S170-74). 
43. Cutler NR, Haxby JV, Duara R, et al. Brain metabolism as measured with positron emission tomography: serial assessment in a patient with familial Alzheimer's disease. Neurology 1985; 35: 1556-1561.

44. Coblentz JM, Mattis S, Zingesser LH, et al. Presenile dementia: clinical aspects and evaluation of cerebrospinal fluid dynamics. Arch Neurol 1973; 29: 299-308.

45. Gellermann LW. Chance order of alternating stimuli in visual discrimination experiments. J Genetic Psychol 1933; 42: 207-208.

46. Oscar-Berman $\mathbf{M}$. The effects of dorsolateral-frontal and ventrolateralorbitofrontal lesions on spatial discrimination learning and delayed response in two modalities. Neuropsychologia 1975; 13:237-246.

47. Rosvold HE. Szwarcbart MK. Neural structures involved in delayedresponse performance. In: Warren JM, Akert K, eds. The Frontal Granular Cortex and Behaviour. New York: McGraw-Hill 1964: 1-15.

48. Isseroff A, Rosvold HE, Galkin TW, et al. Spatial memory impairments following damage to the mediodorsal nucleus of the thalamus in rhesus monkeys. Brain Res 1982; 232: 97-113.

49. Schulman S. Impaired delayed response from thalamic lesions. Arch Neurol 1964; 11: 477-499.

50. Johnson TN, Rosvold HE, Mishkin M. Projections of behaviorally defined sectors of the prefrontal cortex to the basal ganglia, septum and diencephalon of the monkey. Exp Neurol 1968; 21: 20-34.

51. Akert K. Comparative anatomy of frontal cortex and thalamofrontal connections. In: Warren JM, Akert K, eds. The Frontal Granular Cortex and Behavior. New York: McGraw-Hill 1964: 372-396.
52. Walker AE. The Primate Thalamus. Chicago: University of Chicago Press 1938.

53. Hornykiewicz O. Brain dopamine in Parkinson's disease and other neurological disturbances. In: Horn AS, Korf J, Westerink, BHC, eds. The Neurobiology of Dopamine. New York: Academic Press 1979: 633-54.

54. Kish SJ, Rajput A, Gilbert J, et al. Elevated $\gamma$-Aminobutyric acid level in striatal but not extrastriatal brain regions in Parkinson's disease: correlation with striatal dopamine loss. Ann Neurol 1986; 20: 26-31.

55. Mahut H. Spatial and object reversal learning in monkeys with partial temporal lobe ablations. Neuropsychologia 1971;9:409-424.

56. Mahut H, Cordeau JP. Spatial reversal deficit in monkeys with amygdalohippocampal ablations. Exp Neurol 1963; 7: 426-434.

57. Sandson JS, Albert ML. Varieties of perseveration. Neuropsychologia 1984; 6: 715-732.

58. Mishkin M. Perseveration of central sets after frontal lesions in monkeys. In: Warren JM, Akert K, eds. The Frontal Granular Cortex and Behavior. New York: McGraw-Hill Book Company 1964: 219-241.

59. Tomlinson PE. The pathology of dementia. In: Wells CE, ed. Dementia. Philadelphia: FA Davis 1977; 113-153.

60. Albert ML. Subcortical dementia. In: Katzman R, Terry RD, Bick KL, eds. Alzheimer's Disease: Senile Dementia and Related Disorders. New York: Raven Press 1978: 173-180.

61. Cummings JL, Benson DF, eds. Dementia: A Clinical Approach. Boston: Butterworths 1983.

62. Cummings JL, Benson DR. Subcortical dementia. Arch Neurol $1984 ; 41: 874-889$. 